\title{
Complex partial status epilepticus: a recurrent problem
}

\author{
O C Cockerell, M C Walker, J W A S Sander, S D Shorvon
}

\begin{abstract}
Twenty patients with complex partial status epilepticus were identified retrospectively from a specialist neurology hospital. Seventeen patients experienced recurrent episodes of complex partial status epilepticus, often occurring at regular intervals, usually over many years, and while being treated with effective anti-epileptic drugs. No unifying cause for the recurrences, and no common epilepsy aetiologies, were identified. In spite of the frequency of recurrence and length of history, none of the patients showed any marked evidence of cognitive or neurological deterioration. Complex partial status epilepticus is more common than is generally recognised, should be differentiated from other forms of non-convulsive status, and is often difficult to treat.
\end{abstract}

$(\mathcal{F}$ Neurol Neurosurg Psychiatry 1994;57:835-837)

Complex partial status epilepticus (CPSE) with EEG evidence was first described in $1956,{ }^{1}$ and a number of cases have been described since..$^{2-8}$ The condition is heterogeneous and it is often difficult to identify any common factors in the patients. Although it can occur at any age, most patients were between 20 and 40 years of age; most also had a preceding history of epilepsy, usually for many years, with no predominantly encountered aetiology. Various triggers for CPSE have been noted, including alcohol, ${ }^{9}$ drug withdrawal, ${ }^{3}$ infection, ${ }^{2}$ menstruation, ${ }^{10}$ and electroconvulsive therapy. ${ }^{11}$ The clinical phenomenology of CPSE varies widely, but it is usually manifest as variable periods of confusion lasting anything from hours to months with motor features such as myoclonic twitching and automatisms often seen. ${ }^{2-8}$ The EEG features are diverse, showing continuous or frequent spike or spike/slow waves, spike/wave paroxysms which can be widespread or focal, and sometimes periods of desynchronisation. ${ }^{6}$

In spite of the increasing familiarity with many of the aspects of CPSE, there has been little attention paid to the recurring nature of this disorder. We present a case series of patients with CPSE, in which most of the patients had more than one attack, with the majority experiencing numerous attacks, even with adequate treatment for the epilepsy. Most patients also experienced these episodes in regular patterns, but in spite of the large number of total episodes experienced by each patient none of them had any clinical evidence of any consequent neurological damage. We believe that this tendency to regular recurring episodes is an important feature of CPSE and does not usually signify a poor prognosis.

\section{Patients and methods}

We retrospectively examined adult patients with documented CPSE who had attended the epilepsy unit of the National Hospitals for Neurology and Neurosurgery over a period of 1 year. The case definition used was as follows: a prolonged epileptic episode in which focal fluctuating or frequently recurring electrographic epileptic discharges, arising out of temporal or extratemporal regions, result in a confusional state with variable clinical symptoms lasting for more than 30 minutes. Patients who were excluded had absence (petit-mal) status, atypical absence status, and Lennox-Gastaut or similar syndromes; patients were also excluded if there was doubt about the diagnosis. As well as documentation of the clinical and EEG features, particular attention was paid to the frequency and pattern of the attacks of CPSE and any possible triggers.

Results

The demographic and clinical features are summarised in table 1 . The average age of onset of CPSE was 24 years from the onset of the underlying epilepsy. The length of the CPSE usually varied from a few days to a few weeks, with one exceptional case lasting 18 months. All the patients had partial epilepsy. All but three of the patients had repeated attacks of CPSE. Nine patients experienced between one and six attacks per month; three had infrequent episodes, one every five years, the other two episodes every six months; three had only ever had between two and four attacks; and in 11 the CPSE recurred regularly at intervals varying from weekly to twice yearly. None of the patients showed any 
Table 1 Clinical features of subjects

\begin{tabular}{|c|c|c|c|c|c|c|c|c|}
\hline $\begin{array}{l}\text { No } \\
\text { of } \\
\text { cases }\end{array}$ & $\begin{array}{l}\text { Age } \\
\text { (years) }\end{array}$ & Sex & $\begin{array}{l}\text { Age at } \\
\text { seizure } \\
\text { onset } \\
\text { (years) }\end{array}$ & $\begin{array}{l}\text { Age at } \\
\text { onset of } \\
\text { CPSE } \\
\text { (years) }\end{array}$ & $\begin{array}{l}\text { Frequency of } \\
\text { CPSE }\end{array}$ & $\begin{array}{l}\text { Duration of } \\
C P S E\end{array}$ & $\begin{array}{l}\text { EEG characteristics } \\
\text { during CPSE }\end{array}$ & Clinical characteristics \\
\hline 20 & $\begin{array}{l}\text { Mean: } 39 \cdot 7 \\
\text { Range: } 21-80\end{array}$ & $\begin{array}{l}M(15) \\
F(5)\end{array}$ & $\begin{array}{l}\text { Mean: } 9 \cdot 5 \\
\text { Range: } 1-27\end{array}$ & $\begin{array}{l}\text { Mean: } 33 \cdot 2 \\
\text { Range: } 7-80\end{array}$ & $\begin{array}{l}17 / 20 \text { recurrent } \\
11 / 20 \text { periodic } \\
\text { (weekly to twice } \\
\text { yearly) }\end{array}$ & $\begin{array}{l}\text { Usually } 2 \text { days } \\
\text { (hours-18 months) }\end{array}$ & $\begin{array}{l}\text { Focal: } \\
\text { Sharp waves; slow waves; } \\
\text { spikes/slow waves over } \\
\text { frontal or temporal } \\
\text { regions } \\
\text { Generalised: } \\
\text { Spike/slow waves; } \\
\text { polyspikes; slow waves } \\
\text { Cyclical fast and slow activity }\end{array}$ & $\begin{array}{l}\text { Hallucinations; episodic } \\
\text { jerking; confusion; } \\
\text { mutism; anxiety; motor } \\
\text { retardation; automatisms; } \\
\text { variable amnesia. Often } \\
\text { able to feed and obey } \\
\text { simple commands }\end{array}$ \\
\hline
\end{tabular}

marked evidence of clinical or cognitive deterioration; this was in pronounced contrast to our experience with patients with convulsive status. We could only identify five patients in whom more than one psychometric evaluation had been performed over a period of two or more years, and none of the five showed any decline in any of the test scores.

A case that exemplifies the salient clinical features of CPSE in our series was that of a right-handed 25 year old male, who had complex partial and secondary generalised seizures from the age of two and began to have prolonged episodes of confusion from the age of 21 years. From that time he would have weekly episodes, consisting of loss of awareness, confusion, and episodic twitching which could last from a matter of hours to up to two days. During this period, his EEG demonstrated widespread, but predominantly frontal, slow and slow/sharp waves. His epilepsy remains resistant to all treatment, and diazepam given during an episode has little or no immediate effect. MRI has revealed a right insular lesion of unknown aetiology.

\section{Discussion}

Prolonged epileptic states without convulsions have been recognised since the nineteenth century. ${ }^{1213}$ Treiman subdivided non-convulsive status into CPSE, and absence status, ${ }^{7}$ and there have been numerous other proposals for diagnostic categorisation. However, the clinical and EEG features of these subcategories often merge, ${ }^{8}$ and there has been nosological difficulty in the past with a failure correctly to differentiate CPSE from absence status or atypical absence status (AAS). We propose a subdivision of non-convulsive status into seven different categories, and this is shown in table 2. (Our definition of CPSE is given in the Patients and methods section.) We prefer to restrict the term "absence status" to prolonged absence attacks (or absences with no recovery in between) with $3 \mathrm{~Hz}$ spike wave EEG activity occurring in patients with the genetic syndrome of primary generalised epilepsy. ${ }^{14} 15$

CPSE has previously been considered a rare disorder, ${ }^{3}$ with between 60 and 150 cases being described in the literature. ${ }^{716}$ In attempts to ascertain the frequency, Dunne described four cases of CPSE out of a total of 113 patients presenting with status epilepticus of all types to a general hospital, ${ }^{2}$ and Tomson ${ }^{8}$ collected 33 cases, estimating the annual incidence to be 1.5 in 100000 . It is not possible to arrive at a figure for incidence from our results, but our experience in a specialist neurology hospital, which sees only a selected proportion of the epilepsy population, is that up to $15 \%$ of patients who have chronic complex partial seizures have had one or more episodes of CPSE. ${ }^{16}$

A striking feature of these cases is the tendency of the CPSE to recur, often with surprising regularity. Recurrence of CPSE has been noted before. Dunne noted that half of his patients may have had previous episodes, ${ }^{2}$ although it was not clear whether this was in the patients with absence status or CPSE. In another series, Ballinger, studying eight patients of his own and 17 from the literature, noted that eight had had previous attacks. As a result of the highly variable clinical nature of CPSE, and the difficulties of collecting retrospective information, it is probable that many reports have missed previous attacks of CPSE. In this series 11 patients had evidence of recurring attacks, and in some this was in a regular pattern, every week or every month.

Different reasons have been cited previously to explain the recurrence of attacks. Fujiwara $^{17}$ described a patient whose episodes of CPSE were the result of non-compliance. Other stimuli for recurrence are menstruation, and even genetic factors have been implicated. ${ }^{18}$ One of our patients had an attack of CPSE after he stopped his antiepileptic drugs. Even after they were restarted he continued to have further episodes in spite of good compliance. Another patient had been controlled with sulthiame alone, but, on removal of this drug from the UK market, he developed episodes of CPSE that have only

Table 2 Classification of non-convulsive status (NCS)

NCS confined to infancy and childhood:
Syndrome of acquired epileptic aphasia (Landau-Kleffner
or Worster Drought syndrome)
Electrical status epilepticus during slow wave sleep
NCS occurring in childhood and adult life:
Generalised absence status epilepticus
Simple partial status epilepticus (non-convulsive)
Complex partial status epilepticus
NCS in mental handicap (atypical absence status
epilepticus, atonic, and akinetic status)
NCS confined to adult life:
De novo absence status epilepticus of late onset


partially responded to reintroduction of sulthiame (used on a named patient basis). In most cases, however, we were unable to identify a consistent precipitating factor, nor was the aetiology of the epilepsy similar.

In spite of the repeated episodes of CPSE, the lack of evidence for either local damage or more generalised cerebral dysfunction is noteworthy when contrasted with the morbidity and mortality of convulsive status. This is unexpected because of the neurological damage from convulsive status is said to be caused by the persisting cerebral discharges and build up of excitatory neurotransmitters, rather than by hypoxia or poor cerebral perfusion which accompanies convulsive status. ${ }^{7}$ Well documented serial pyschometry was performed in only a small number of patients in this study, but there was no marked clinical evidence of cognitive decline or any other sign of neurological deterioration in the other patients. Evidence that CPSE causes serious neuronal loss has prompted most authors to recommend treating CPSE in the same way as convulsive status, if necessary with general anaesthesia to halt all cerebral EEG activity. ${ }^{7}$ This policy carries a high morbidity and should be weighed against the generally good outlook we found in our patients.

Treating the episodes of CPSE is difficult. In our series the response to intravenous benzodiazepines was variable. Three patients showed EEG and some clinical improvement, whereas one had an EEG response but remained in CPSE. One of our cases persisted in CPSE for 18 months in spite of vigorous treatment-even longer than a similar case which lasted for 7 months. ${ }^{19}$ These observations are in agreement with others about the resistance of CPSE to standard treatments. ${ }^{8}$ There is also a variable response to attempts to prevent further attacks of CPSE with anti-epileptic drugs. Although valproate may be successful in the prevention of absence status, ${ }^{20}$ this has not been substantiated in CPSE. Of our 20 patients, 19 were on standard anti-epileptic drugs, and yet they continued to have further attacks. One patient showed a worthwhile reduction in the number of CPSE episodes after starting carbamazepine, and another patient later underwent a temporal lobectomy and did not have any subsequent episodes of CPSE. Clearly, further work is needed to clarify the long term prognosis of patients with this disorder before a policy of more aggressive intervention can be recommended.

We wish to thank Action Research for their generous support, as well as consultant staff of the National Hospitals for Neurology and Neurosurgery who allowed us to report on their patients.

1 Gastaut H, Roger J, Roger A. Sur la signification de certaines fugues epileptiques: etats de mal temporal. $R e v$ Neurol 1956;94:298-301.

2 Dunne JW, Summers QA, Stewart-Wynne EG. Non-convulsive status epilepticus: a prospective study in an adult vulsive status epilepticus: a prospective stud

3 Engel J, Ludwig BL, Fetell M. Prolonged partial complex status epilepticus: EEG and behavioural observations. status epilepticus: EEG
Neurology 1978;28:863-9.

4 Willamson PD, Spencer DD, Spencer SS, Novelly RA, Mattson RH. Complex partial status epilepticus: a depth electrode study. Ann Neurol 1985;18:647-54.

5 Weiser HG. Temporal lobe or psychomotor status epilepticus: a case report. Electroencephalogr Clin Neurophysiol 1980;48:558-72.

6 Ballinger CE, King DW, Gallagher BB. Partial complex partial status epilepticus. Neurology 1983;33:1545-52.

7 Treiman DM. Status epilepticus. In: Laidlaw J, Richens A, Chadwick D, eds, $A$ textbook of epilepsy. Edinburgh: Churchill-Livingstone, 1993:205-20.

8 Tomson T, Lindbom U, Nilsson BY. Nonconvulsive status epilepticus in adults; thirty two consecutive patients from a general hospital population. Epilepsia 1992;33: 829-35.

9 Fujiwara T, Watanabe M, Matauda K, Senbongi M, Yagi K, Seino M. Complex partial status epilepticus caused by ingestion of alcohol: a case report. Epilepsia 1991;32: 650-6.

10 Zappoli R, Zaccara G, Arnetoli RG, Amantini A. Combined partial temporal and secondary generalised status epilepticus. Eur Neurol 1983;22:192-204.

11 Varma NV, Lee SI. Nonconvulsive status epilepticus following electoconvulsive therapy. Neurology 1992;42: 263-4.

12 Taylor J. Selected writings of John Hughlings Jackson. On epilepsy and epileptiform convulsions, vol. 1. London: Hodder \& Staughton 1931.

13 Lennox, W. The petit mal epilepsies: their treatment with tridione. $\mathcal{F} A M A$ 1945;129:1069-73.

14 Editorial. Non-convulsive status epilepticus. Lancet 1987; ii:958-9.

15 Sander JWAS, Hart YM, Trevisol-Bittencourt PC. Absence status. Neurology 1990;40:1010.

16 Shorvon SD. The clinical forms of status epilepticus. Status epilepticus. Cambridge: Cambridge University Press 1993:35-107.

17 Fujiwara T, Watanabe M, Nakamura H, Kudo T, Yagi K, Seino $M$. A comparative study of absence status epilepticus between children and adults. $\mathcal{F p n}_{p} \mathcal{f}$ Psychiatry Neurol 1988;42:497-508.

18 Brincotti M, Mazzei C, Gallet F, Matricardi M. Genetic aspects of nonconvulsive status epilpticus. Eur Neurol 1991;31:384-7.

19 Roberts MA, Humphrey PRD. Prolonged complex partial status epilepticus: a case report. $\mathcal{f}$ Neurol Neurosurg Psychiatry 1988;51:586-92.

20 Berkovic SF, Anderman F, Guberman A, Hipola D, Bladin PF. Valproate prevents the recurrence of absence Bladin PF. Valproate prevents the
status. Neurology 1989;39:1294-7. 